\title{
de Lucas, Javier. Nosotros, que quisimos tanto a Atticus Finch. De las raíces del supremacismo, al Black Lives Matter. Tirant lo Blanch: Valencia, 2020.
}

Ángeles Solanes Corella

Universitat de València

Fecha de recepción 06/12/2020 I De publicación: 28/12/2020

La figura de Atticus Finch, durante décadas, ha sido vista como un referente para los profesionales del Derecho y un modelo para los estudiantes que se inician en el ámbito de lo jurídico. El éxito multitudinario de la novela de Nelle Harper Lee Matar a un ruiseñor y su adaptación al cine en la película de Robert Mulligan, consolidaron a Finch como un ideal, que de nuevo cobró notoriedad con la publicación, en 2015, de la obra de la misma autora Ve, pon un centinela. El magistral libro que presenta Javier de Lucas, retoma el personaje de Atticus Finch y nos propone un análisis riguroso de una cuestión transcendental y atemporal: el mal que supone el racismo. Este ensayo es fruto de una conjunción nada común: por una parte, la brillante trayectoria del autor, que ha dedicado buena parte de su obra a la investigación de los problemas del racismo y de la lucha contra la discriminación que sufren diferentes minorías por motivos etnoculturales; y por otra, la condición de cinéfilo empedernido del profesor De Lucas, firme defensor de comprender y enseñar el Derecho desde el cine como herramienta, para lo cual se adentra minuciosamente en los entresijos que envuelven a la película en cuestión y, en este caso, en las novelas con las que se relaciona.

Esta obra se divide en dos partes que diferencian los dos ejes centrales de análisis: la reflexión sobre la figura de Atticus Finch, y los argumentos para entender por qué el racismo y el supremacismo siguen presentes en la democracia estadounidense enmascarados desde un esfuerzo negacionista.

La primera parte del libro analiza el personaje de Atticus Finch desde su complejidad, es decir, deja claro que no se trata tanto de mantenerlo como un mito del Derecho, cuanto de entender e interpretar la evolución tan radical que sufre de una novela a otra y el alcance de la misma, en el complejo escenario esclavista, supremacista y racista del Sur. La finalidad de este atrayente recorrido no es otra que evidenciar que ese racismo sigue existiendo y no podemos obviarlo. 
El capítulo primero adentra al lector en el personaje de Finch tal como lo concibió N. H. Lee. Es fundamental para comprender a Atticus atender tanto al ámbito temporal como al entorno espacial (la pequeña ciudad de Maycomb) inmutable. Mientras Matar a un ruiseñor se desarrolla entre 1932 y 1935 , en medio de la Gran Depresión, la segunda novela, Ve, pon un centinela, nos lleva a los años 50 con una evolución del personaje de Finch que va del modelo de juristas al reprobable supremacista blanco. En esa dimensión temporal es central la mirada de Scout, la hija de Atticus de 6 años, que narra en primera persona el libro inicial, mientras que en el segundo un narrador impersonal muestra la decepción que siente la joven Jean-Louis Finch cuando regresa de vacaciones a su pueblo natal, Maycomb, y advierte el drástico cambio en su padre. Ese enfoque transversal que recorre el tiempo centra el núcleo de la narración que no es otro el de la pérdida de la inocencia, no solo de los niños, sino como hábilmente apunta De Lucas, de los adultos y de todo un país. Desde esa mirada también se percibe que la sociedad de castas (y dentro de ella la importancia del origen inglés de la familia de Atticus) no se ha modificado. Es más, la persistente sociedad clasista, segregacionista y racista de Maycomb, ejemplifica, como argumenta el autor de este ensayo, el nexo, especialmente evidente en los estados del Sur, entre el modelo económico, el esclavismo, la ideología del racismo y del supremacismo que infecta el sistema social y político norteamericano hasta la actualidad.

Al análisis de la primera etapa del personaje Atticus Finch, se dedica los capítulos segundo y tercero para examinarlo como un "hombre de Derecho", desde los valores y los principios, y como abogado. De Lucas utiliza esa denominación como hombre de Derecho, no desde la visión del positivismo legal formalista, si no desde la dimensión que le confiere, por ejemplo, Jhering. Es decir, por tal hay que entender a quien trata de encontrar una aproximación a lo "justo concreto", a lo que el Derecho debe proteger desde la garantía de los derechos fundamentales y la asunción del conflicto como elemento constitutivo de la realidad social. La noción de Derecho que Atticus practica, parte de la actitud esencial de la empatía que orienta su conducta de rechazo a la discriminación y a la violencia considerada como el verdadero negativo de lo jurídico.

El segundo rasgo de Atticus Finch como hombre de Derecho, en Matar a un ruiseñor, se sintetiza en lo que puede considerarse su código, es decir, en los elementos centrales del código deontológico de un abogado que remite a cinco reglas básicas que reformulan las de Ulpiano. Atticus constituye un referente en la deontología del abogado si esta se entiende, desde la perspectiva de David Luban, como vinculada al derecho de defensa, a la noción de dignidad que va unida al "derecho a tener voz" que 
permite evitar la condición de infrasujeto. A pesar de la aparente sencillez de este código, no es fácil de ejecutar y, por ello, puede generar frustración, como les ocurre a los hijos del protagonista.

La otra cara de Finch, patente en la segunda novela, nos acerca a las raíces del supremacismo blanco. Para entender este nuevo enfoque que presenta a un Atticus miembro del movimiento supremacista y segregacionista Citizen's Council, hay que tomar en consideración que se trata de un manuscrito anterior al momento en el que se presenta, y, por tanto, fruto de la reescritura que realiza Lee entre 1957 y 1960. Esa contextualización, como apunta Javier de Lucas, es fundamental porque ayuda a comprender que el cambio en el personaje de Atticus está, en buena medida, marcado por la tensión que produjo en los estados del Sur la jurisprudencia antisegregacionista del Tribunal Supremo en casos como Brown vs Board of Education y Browder vs Gayle.

Entre las lecciones interesante que se desprenden de la precuela, el autor de este ensayo siguiendo a Crumm, destaca la referencia a la idea de que la lucha contra la discriminación no acaba con el reconocimiento jurídico de la igualdad, que es condición imprescindible pero no suficiente. Para ello es necesario una verdadera revolución social. Basta leer, podríamos añadir, los informes del relator especial sobre las formas contemporáneas de racismo, discriminación racial, xenofobia y formas conexas de intolerancia, para confirmar la actualidad en nuestros días de esta afirmación, no solo en el caso norteamericano. Aunque el modelo social y económico no esté ya basado en la esclavitud de las personas negras, existen otras formas modernas de esclavitud como la de los inmigrantes en situación administrativa irregular.

En la segunda novela, está presente de manera expresa la idea de que el momento de la igualdad racial aún no ha llegado. Es más, queda patente la relación de Atticus con el Ku-Klux-Klan. Ciertamente, incluso en Matar a un ruiseñor, Finch no defiende un optimismo antropológico en base al cual podría considerarse que todos los seres humanos nacen iguales, si no más bien que ante el Derecho "todos deben ser iguales".

El profesor De Lucas en la reconstrucción que lleva del Atticus de una novela al de la otra, hábilmente llama la atención sobre tres consideraciones que permiten establecer una cierta continuidad entres ambos, y salvar al Finch de la segunda novela de la condena de ser visto únicamente como un supremacista. En primer lugar, aunque la conducta de Atticus decepcione, persiste la rectitud de su conciencia, esa que funciona como centinela. Además, en segundo lugar, sigue siendo un hombre de 
Derecho, con la convicción del respeto a la ley y la prioridad de que todos puedan expresar su opinión. Por último, como reflexión que John dirige a Jean-Louise, la necesidad de pensar con la propia cabeza, guiada por la conciencia, y superar así la imagen idealizada que la niña de 6 años tenía sobre su padre para admitir que es un ser humano y que ella debe guiarse por la razón. De esta manera, la niña Scout que concebía a su padre como el ideal de justicia, es ahora la joven Jean-Louise que lo ve como un hombre imperfecto.

El capítulo quinto, que cierra la primera parte de este ensayo, se dedica al análisis del ideario político de Atticus, en concreto a su concepción como demócrata jeffersoniano. Javier De Lucas realiza un interesante recorrido por los rasgos básicos de la democracia republicana de la mano de expertos como Maiz y Aldrich, que permite entender ese peculiar modelo de "democracia de los pequeños propietarios", pensado para el mantenimiento de la estructura social de los estados del Sur. Desde esta interpretación republicada de Jefferson y Madison, el modelo constitucional norteamericano estaría marcado por el necesario desarrollo de la libertad de los ciudadanos como individuos, la consideración del gobierno federal como un "mal" necesario para la exigencia del bien común contrarrestado con la libertad de expresión y prensa, y la visión del poder judicial como instrumento al servicio de los representantes elegidos sin que el Tribunal Supremo pueda bloquear las leyes aprobadas por el Congreso.

En ese contexto encaja la concepción de democracia de Finch, sin olvidar su configuración como hombre de Derecho, con una importante divergencia respecto a Jefferson que De Lucas analiza para que pueda entenderse la evolución, nada simple, del personaje en toda su extensión. En efecto, Atticus a diferencia de Jefferson es un enemigo de la esclavitud. Aunque no pueda librarse de la mirada paternalista que inspira su opinión hacia los negros, no puede afirmarse, como ocurre en el caso de Thomas Jefferson, que esté convencido de la superioridad de la raza blanca y sea partidario de la segregación más radical desde la mirada utilitarista a la esclavitud. El ideal democrático de Atticus se identifica con la concepción de derechos iguales para todos, sin privilegios, pero no consigue librarse del racismo y el supremacismo que inspiran el experimento democrático de 1776.

Precisamente ese "pecado original" de la democracia norteamericana, que en sus propios orígenes no consigue librarse del racismo, es el punto de inicio de la segunda parte de este magnífico libro, que incluye los capítulos sexto a octavo. 
Las novelas de N. H. Lee analizadas en la primera parte de este ensayo se entrelazan hábilmente en la segunda como hilo conductor para abordar la continuidad del racismo y el segregacionismo en los EE. UU., a pesar de los diferentes intentos de combatirlo. El capítulo sexto comienza por una reflexión sobre el fenómeno de la esclavitud y su especial significado en el ámbito norteamericano de la mano de Davis. Resulta sumamente interesante y esclarecedor bucear en el negocio de la esclavitud como un sistema complejo y multifactorial no solo circunscrito al caso norteamericano sino a la "economía triangular de la esclavitud", es decir, al comercio entre Europa, África y América. Javier de Lucas realiza un sugerente recorrido de la mano de diferentes estudiosos del momento fundacional norteamericano y sus repercusiones posteriores, desde diferentes perspectivas, y trae a colación momento históricos ineludibles (como el discurso de Martin Luter King en la marcha sobre Washington) para evidenciar que siguen siendo patentes las consecuencias del pasado racista no superado que limita el futuro.

De los diferentes aspectos que el profesor De Lucas aborda, considero que, por su alcance, pueden destacarse dos: la importancia de las tres Enmiendas a la Constitución (tras la famosa Proclamación de la Emancipación de Lincoln) y la amnesia colectiva que parece afectar a la sociedad norteamericana en la relativo al racismo y el segregacionismo.

La aprobación de la XIII Enmienda supuso la abolición de la esclavitud y la servidumbre involuntaria, la liberación de los esclavos y la proclamación de su igualdad ante la ley. La XIV Enmienda completó el reconocimiento de la condición de ciudadano a las personas nacidas o naturalizadas en EE.UU., el derecho al debido proceso y la igualdad de protección. Y finalmente la XV Enmienda prohibió la discriminación por motivos raciales en el derecho al voto.

Sin embargo, la XIII Enmienda introdujo una importante excepción en el caso de castigo por un delito, que a menudo pasa desapercibida cuando en realidad tuvo un importante efecto práctico. Al amparo de esta excepción durante la Reconstrucción, posterior al final de la guerra civil, se aprobaron los denominados Códigos Negros que permitieron que continuara la esclavitud de facto al imponer limitaciones a la movilidad para trabajar, un sistema de multas y castigos corporales, y la posibilidad de servidumbre por deudas. Estos instrumentos jurídicos dieron progresivamente paso, en algunos estados del Sur, a un conjunto de leyes racistas, las denominadas leyes Jim Crow, cuya finalidad no era otra que la de mantener el régimen de segregación. 
Resulta llamativo el hecho de que, aunque la esclavitud desapareció formalmente en Estados Unidos entre la mitad y el último tercio del siglo XIX, en realidad siguió existiendo de manera encubierta en algunos estados del Sur. Hasta tal punto que, por ejemplo, el estado de Mississippi no ratificó formalmente la aprobación de la mencionada XIII Enmienda hasta el año 2020, aunque desde 1995 existía el acuerdo favorable de su Cámara para tal ratificación.

Ante esa falta de reconocimiento de la igualdad, o lo que es lo mismo, la continuación del "pecado original" que daña desde su gestación a la democracia norteamericana, se advierte una especie de amnesia colectiva o incluso de gran negación por parte de la sociedad en EE UU. En este punto, Javier de Lucas no evita abordar la cuestión, siempre controvertida, de qué hace que se dé dicha amnesia o al menos el enmascaramiento de la realidad. Para ahondar en las razones que llevan a esos procesos sociales de negación de la memoria o de construcción del olvido, desde referentes como Todorov, De Lucas apela al caso alemán y llega a la propuesta de Schwarz respecto a la actitud de indiferencia. En efecto, como mantiene la mencionada autora esa actitud de indiferencia se identifica básicamente con los seguidores, los simpatizantes o "los compañeros de viaje", es decir, aquellos que por oportunismo, conformismo o apatía se convierten en cómplices de prácticas o ideas criminales, podría añadirse que en la línea que señalaba Arendt a propósito de la conocida "banalidad del mal". Esa indiferencia, que se encuentra en la base del negacionismo, puede asociarse con los peores crímenes contra la humanidad.

EE.UU. puede considerarse un buen ejemplo del denominado racismo institucional que perpetua la subordinación y discriminación de los sujetos atendiendo a su “identidad racial”. Ese racismo institucional viene necesariamente acompañado del modelo segregacionista que se conjuga con el supremacismo y se relaciona directamente con la ya mencionada sociedad de castas. Precisamente dicha estructura de castas, como apunta De Lucas en el capítulo séptimo de este ensayo, permite naturalizar el racismo, justificarlo, incluso podría considerarse que conjugado con la indiferencia lo normaliza. La sociedad de Maycomb es un laboratorio que muestra a la perfección ese sistema oculto de dominación social. La evolución del personaje de Atticus evidencia una progresiva aceptación de ese orden social, más inequívoca en la segunda novela, posiblemente porque entiende que las personas negras aún "no están listas" para la igualdad.

Llama la atención en el funcionamiento de este sistema de castas el hecho de que, en la primera novela, esa forma de exclusión evidente es aceptada por los propios agraviados: los negros, como ejemplifica el caso de Calpurnia, la aya negra. En la precuela Calpurnia ya no se somete a ese orden 
natural de las cosas en Maycomb, sino que cuestiona el trato que reciben de los amos a pesar de la promesa constitucional de igualdad.

De Lucas se detiene en el análisis de la estigmatización que sufre la población negra, esa discriminación tan arraigada que, en ocasiones, casi invierte el principio de presunción de inocencia. Entre las situaciones a las que dicha comunidad tiene que hacer frente resulta especialmente grave la relativa a la violencia policial. A propósito de dicha violencia, es relevante la transformación que ha sufrido la práctica denominada the talk (la conversación). En la actualidad, la conversación hace referencia a la necesidad de que los padres negros expliquen a sus hijos el riesgo que corren ante la policía por el color de su piel. Se pone así en evidencia que para los negros (como para los inmigrantes irregulares, por ejemplo), en uno de los estados más poderosos del mundo, como lo es EE.UU., no rigen las reglas del Estado de Derecho. Más bien al contrario, el racismo sistemático, estructural, hace que el color de la piel per se resulte una sospecha suficiente para invertir los mecanismos del Estado de Derecho. Como si se aplicara, en el peor de los casos, los postulados del derecho penal del enemigo que defendía Jacobs o, al menos, un paternalismo propio de la tutela que ejerce el supremacismo.

La historia de EE. UU. está marcada por la lucha contra la esclavitud, por la permanente promesa de libertad incumplida. Entre los protagonistas en esa lucha Martín Luther King ocupa un lugar preferente. Precisamente, siguiendo a Jones, De Lucas analiza las diferentes formas en las que legado de King ha caído en el olvido, lo que denomina "los tres entierros de su legado". En el capítulo octavo aborda las principales ideas de King y su actualidad, puesto que como señaló en una de sus principales obras la comunidad negra ya no puede esperar más porque "esperar" significa "nunca". Sin la importante labor del premio Nobel de la paz (1964), todas las mejoras legislativas que vinieron después no hubieran sido posibles. Sin embargo, desafortunadamente, la deuda que destacaba en la parte más celebre de su discurso en la marcha de Washington sigue pendiente: "el cheque que la justicia debía al hombre negro en los EE. UU., desde su fundación”. Ese débito pendiente que en la práctica supone violencia y brutalidad policial, arbitrariedad y un racismo en el sistema penal y penitenciario contra los negros, ha alentado movimientos como Black Lives Matter que vuelven sobre las exigencias de igualdad. Dicho movimiento exige retomar las promesas de los founding fathers y las reivindicaciones de derechos civiles de los años 50 y 60 porque los afroamericanos tiene claro que quieren ya el pago de ese cheque.

Frente a los logros que permitían vislumbrar pequeños avances para combatir la discriminación, en la historia más reciente norteamericana se han dado importantes retrocesos. La presidencia de Trump, 
como apunta De Lucas, ha supuesto una regresión en la lucha por la igualdad, no solo para los negros si no también para los inmigrantes que se han convertido en objetivo reiterado de promesas ligadas a la ideología supremacista y racista. Como se evidenció en la última campaña electoral, Trump estaba dispuesto a rentabilizar y profundizar en la división de la nación, en el enfrentamiento entre los partidarios de la ley, el orden, la defensa de las fuerzas policiales y los defensores de una "América grande" y, de otro lado, los que causan disturbios y se enfrentan a la policía. La victoria de Biden y Harris puede suponer una nueva oportunidad para alcanzar, de una vez por todas, la libertad prometida.

Los EE. UU. en la actualidad siguen siendo una nación divida, tanto o más que en las obras de Lee. En efecto, las dos novelas y la película no hablan solo de raza, justicia y equidad si no "de meterse en la piel de alguien y caminar en ella", de la empatía de Finch con la que afrontar esa división. Si se hace este esfuerzo, para curar la herida de la desigualdad, harán falta generaciones leales a los principios del Estado de Derecho. Esas futuras generaciones deberían actualizar y asumir el espíritu de Atticus, desde el lúcido análisis que ofrece este libro de Javier de Lucas, que es un hombre de Derecho, un firme convencido de que el racismo y el supremacismo son incompatibles con la verdadera democracia. 